\title{
Retractation note: Étudier les marqueurs épistémiques et évidentiels du français tels qu'ils émergent dans la parole-en- interaction. Synthèse critique de la littérature existante
}

Jérôme Jacquin

Withdrawn article: SHS Web of Conferences 78, 01007 (2020), https://doi.org/10.1051/shsconf/20207801007

This article has been mistakenly published in this volume and has been withdrawn at the request of the author and the scientific editors. 